\title{
Mr Smits goes to Brussels
}

\section{Enthusiastic welcome for new European research chief.}

He doesn't own a car, preferring on principle to walk whenever possible. And he buys his own sandwiches. But Robert-Jan Smits, Europe's down-to-earth new research chief, is utterly at home in the rarefied world of European Union (EU) bureaucracy.

Smits, who will become director general for research on 1 July — in time to oversee the gestation and birth, in 2014, of the European Commission's multibillion-euro Eighth Framework Programme for research - ascended to the post in record time. And he arrives with considerable goodwill among the researchers whose lives will be affected by his decisions.

The research director general is responsible for drafting all research funding initiatives for approval by the European Parliament and Council, the EU's legislative bodies. He is also charged with ensuring the smooth running of all elements of the EU Framework programmes - from postdoctoral fellowships to the huge international fusionenergy project ITER.

Commission staff and scientists who deal with the commission are openly thrilled. "We are all so enthusiastic about this appointment," says Helga Nowotny, president of the European Research Council (ERC), the basic-research granting agency. Nowotny is normally critical of the commission and its frustrating bureaucracy. But, she says, Smits "has a good track record, and he understands research issues extremely well".

"The appointment is terrific news," adds materials scientist John Wood, principal of Imperial College London and chair of the European Research Area Board, which promotes the unification of European research efforts. "He may be a bit bureaucratic at times, but he is a listener, and is always trying to find solutions to problems."

Such unaccustomed praise for a top European bureaucrat also reflects widespread relief at the departure of the unpopular incumbent, José Manuel Silva Rodríguez, who becomes an adviser to commission president José Manuel Barroso. Silva Rodríguez arrived in 2005 from the commission's agriculture directorate, and critics say he rigidly applied its strict accounting culture to research without understanding scientists' need for flexibility. Researchers complain that they are being crushed by the detailed accounting expected of them (see Nature 465, 666; 2010).
By contrast, Smits, a natural consensus-seeker, understands how researchers can best be served, even within the restrictive commission rules, say his supporters. Much is at stake in his success, because the commission's Framework programmes are not only financially significant, they influence much of the research agenda in Europe. Yet they work badly, and scientists find the procedures for participating in them discouragingly complex.

Smits, at 52, is considered young for this high position. Trained in international law in his native Netherlands, then in Switzerland and the United States, he has become steeped in the research culture since joining the commission in 1992. He has been in charge of issues as diverse as research infrastructures, such as biobanks, and the relations between the commission and facilities such as CERN, the particle-physics laboratory near Geneva, Switzerland. In April, he became deputy director general of the Joint Research Centre, which conducts research for EU policy-makers, a position he will now relinquish.

Smits has a pronounced pro-industry spin, colleagues say. This has not unnerved scientists who have watched him enthusiastically assist the 2007 birth of the popular ERC. And it actively endeared him to EU commissioner Máire Geoghegan-Quinn, who took office in February (see Nature 463, 722-723; 2010). Insiders say Geoghegan-Quinn quickly spotted him as someone who would deliver on her two key missions: to bring research closer to the innovation pipeline and to simplify procedures to make them more attractive to scientists.

The commissioner, who prides herself on being 'a doer', surprised everyone by getting Smits into his post so quickly. Silva Rodríguez could not have stayed beyond the end of this year (the director general cannot hold the post for more than 5 years), but Geoghegan-Quinn exercised her prerogative to make the change early. As the person responsible for achieving the top-level research objectives set by GeogheganQuinn, Smits's relationship with her will be key to his success, says Silva Rodríguez's predecessor, Achilleas Mitsos. "If you have a good trusting relationship with your commissioner, you can get things done," he says. That seems likely to be the case for Smits and Geoghegan-Quinn, he adds. "They share a similar philosophy."

Alison Abbott 